\title{
Polypharmacy and Potential Inappropriate Drug Use in The Elderly Admitted to the General Internal Medicine Outpatient Clinic
}

\author{
Celaleddin DEMİRCAN ${ }^{1}$, Ulviyya HASANZADE ${ }^{1}$ \\ ${ }^{1}$ Bursa Uludağ University Medical Faculty, Department of Internal Medicine, Bursa, Turkey
}

Turk J Int Med 2021;3(Supplement 1):S46-S48

DOI: $10.46310 /$ tjim. 879724

Keywords: Polypharmacy, potential inappropriate drug, elderly

The frequency of chronic diseases, the number of drugs used, the rates of polypharmacy and consequently, the risks of potentially inappropriate drug (PID), drug-drug interactions and drug adverse reactions have increased in the elderly.,2 In this study, we aimed to investigate the rates of polypharmacy and PIDs use in elderly patients who admitted to General Internal Medicine Outpatient Clinic of Uludag University Hospital. It was planned as a prospective cross-sectional study. The sociodemographic characteristics, diagnoses, concomitant chronic diseases and the drugs they used were recorded in detail through face-to-face interviews with the patients on the previously prepared questionnaire form. Then, the files of the patients were examined, and the diseases and drugs information were confirmed.

In this study, daily use of 5 drugs was accepted as polypharmacy. ${ }^{3}$ After then, the drugs used by the patients were evaluated in terms of PIDs according to the 2015 Beers Criteria. ${ }^{4}$ According to these criteria, PIDs are grouped as follows;
1. Table 2-related PIMs: Taking drugs that should be avoided in the elderly.

2. Table 3-related PIMs: Taking drugs that should be avoided due to drug-disease or drugsyndrome interactions in the elderly.

3. Table 4-related PIMs: Inappropriate use of drugs that should be used with caution in the elderly.

4. Table 5-related PIMs: Taking drugs that should be avoided due to clinically important drug-drug interactions in the elderly.

5. Table 6-related PIMs: Inappropriate use of drugs that should be avoided or reduced in dosage due to renal impairment in the elderly.

SPSS 21 package program was used for data analysis. Pearson Chi-Square and Fisher's exact Chi-Square tests were used for comparison of categorical variables, the Kruskal-Wallis test was used to compare more than two independent groups, and the Mann-Whitney U test was used to compare two independent groups.

In a 4-month period (from September 1 to

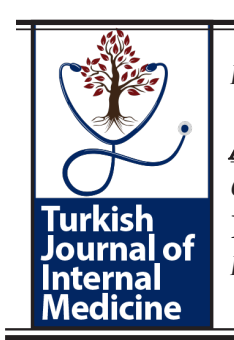

Received:February 14, 2021;Accepted:March 5, 2021; Published Online:March 6, 2021

Bursa Uludağ University Faculty of Medicine, Department of Internal Medicine, Bursa, Turkey

E-mail:demircan@uludag.edu.tr 
Table 1. The distribution of the number of drugs used and potential inappropriate drugs by gender and geriatric age groups

\begin{tabular}{lccccc} 
& \multicolumn{2}{c}{ Gender } & Total & \multicolumn{2}{c}{ Age Group } \\
& Female & Male & & 65-74 years & 275 years \\
\hline Number of drugs used & & & & & \\
No drug & $6(3.4 \%)$ & $5(4 \%)$ & $11(3.6 \%)$ & $10(4.1 \%)$ & $1(1.6 \%)$ \\
- 1-4 drugs & $73(40.8 \%)$ & $59(47.2 \%)$ & $132(43.4 \%)$ & $105(43.2 \%)$ & $27(44.3 \%)$ \\
- 5-9 drugs & $86(48 \%)$ & $55(44 \%)$ & $141(46.4 \%)$ & $114(46.9 \%)$ & $27(44.3 \%)$ \\
- $\geq \mathbf{1 0}$ drugs & $14(7.8 \%)$ & $6(4.8 \%)$ & $20(6.6 \%)$ & $14(5.8 \%)$ & $6(10 \%)$ \\
Potential inappropriate medications & & & & \\
\hline Table 2-related PIDs & $54(30.7 \%)$ & $32(25.6 \%)$ & $86(28.3 \%)$ & $53(21.8 \%)$ & $33(54.1 \%) *$ \\
Table 3-related PIDs & $7(3.9 \%)$ & $5(4 \%)$ & $12(3.9 \%)$ & $8(3.3 \%)$ & $4(6.6 \%)$ \\
Table 4-related PIDs & $6(3.4 \%)$ & $5(4 \%)$ & $11(3.6 \%)$ & $3(1.2 \%)$ & $8(13.1 \%)$ \\
Table 5-related PIDs & $8(4.5 \%)$ & $4(3.2 \%)$ & $12(3.9 \%)$ & $8(3.3 \%)$ & $4(6.6 \%)$ \\
Table 6-related PIDs & $2(1.1 \%)$ & $1(0.8 \%)$ & $3(9.9 \%)$ & $2(0.8 \%)$ & $1(1.6 \%)$ \\
\hline
\end{tabular}

$* \mathrm{p}<0.001$

December 31, 2020), 304 (58.9\% female, 41.1\% male) patients who gave informed consent were included in the study. The mean age of the patients was $71.5 \pm 5.2 .95 .8 \%$ had at least one concomitant chronic disease, the mean number of chronic diseases was $2.7 \pm 1.6$ and the most common chronic diseases were hypertension (67.1\%) and diabetes mellitus (39.8\%). The daily mean number of drugs used by the patients was $4.9 \pm 3.3$ and the rate of polypharmacy was $52.9 \%$. A total of 124 PIDs were observed in 104 (34.2\%) patients, and this rate was higher in patients with polypharmacy $(p<0.05)$ (Table 1). Table 2- and Table 4-related PIDs were higher in the $\geq 75$ age group. There was no difference between gender and age groups in terms of other categories. The most common PID was the use of drugs that should be avoided in the elderly (Table 2-related PIDs, 28.3\%). On the basis of drugs, the most common of these was the inappropriate use of proton pump inhibitors (PPI) $(n=30,9.9 \%)$ and potent anticholinergics $(n=23$, $7.6 \%)$.

The rates of polypharmacy were reported as $47.6 \%$ in a study that patients admitted to a geriatric outpatient clinic in Turkey ${ }^{5}, 59.6 \%$ in a study that patients living in nursing homes in Turkey ${ }^{6}, 47 \%$ in a study that patients admitted to the hospital in Norway ${ }^{7}$ and $51.9 \%$ in another study in Italy. ${ }^{8}$ The rates of PIDs in studies using Beers 2015 criteria were reported as $60 \%$ in a study in two assisted living facilities in the $\mathrm{USA}^{9}$ and $29.3 \%$ in another study at the time of admission to internal medicine and surgical services in Jordan, and in the latter study PPIs were the most common PIDs. ${ }^{10}$ Similarly, in this study, we observed that the number of chronic diseases, polypharmacy and PIDs rates were high in the elderly, and there was a linear correlation between polypharmacy and PIDs, and PPIs were the most commonly used PIDs. Therefore, in order to reduce the possible risks that may occur in the elderly, patients should be examined by a comprehensive geriatric assessment, drugs should be prescribed according to rational drug use recommendations, the drugs used in terms of PIDs should be evaluated, and patients should be explained in detail how to use their drugs. Then, at each visit, they should be carefully questioned in terms of how they use the drugs and drug adverse effects.

\section{Conflict of Interests}

Authors declare that there are none.

\section{Acknowledgment}

This study has been presented in $17^{\text {th }}$ Uludag Internal Medicine National Winter Congress, $6^{\text {th }}$ Bursa Family Medicine Association National Congress, $11^{\text {th }}$ Uludag Internal Medicine Nursing Congress, 5-7 March 2021, Bursa, Turkey. 


\section{References}

1. Almeida AM, Ramos F. Acute myeloid leukemia in Nobili A, Garattini S, Mannucci PM. Multiple diseases and polypharmacy in the elderly: challenges for the internist of the third millennium. J Comorb. $2011 \mathrm{Dec}$ 27;1:28-44. doi: 10.15256/joc.2011.1.4.

2. Hanlon JT, Lindblad CI, Hajjar ER, McCarthy TC. Update on drug-related problems in the elderly. Am J Geriatr Pharmacother. 2003 Sep;1(1):38-43. doi: 10.1016/s1543-5946(03)80014-4.

3. Kaufman DW, Kelly JP, Rosenberg L, Anderson TE, Mitchell AA. Recent patterns of medication use in the ambulatory adult population of the United States: the Slone survey. JAMA. 2002 Jan 16;287(3):337-44. doi: 10.1001/jama.287.3.337.

4. By the 2019 American Geriatrics Society Beers Criteria ${ }^{\circledR}$ Update Expert Panel. American Geriatrics Society 2019 Updated AGS Beers Criteria for potentially inappropriate medication use in older adults. J Am Geriatr Soc. 2019 Apr;67(4):674-94. doi: 10.1111/jgs.15767.

5. Bahat G, Tufan F, Bahat Z, Tufan A, Aydin Y, Akpinar TS, Nadir S, Erten N, Karan MA. Comorbidities, polypharmacy, functionality and nutritional status in Turkish community-dwelling female elderly. Aging Clin Exp Res. 2014 Jun;26(3):255-9. doi: 10.1007/ s40520-014-0229-8.
6. Gocer S, Gunay O, Polat T, Ulutabanca RO, Sonkaya ZI. Polypharmacy and associated factors in people living in a nursing home in Kayseri Turkey. Medicine Science 2017;6(4):646-52. doi: 10.5455/ medscience.2017.06.8633.

7. Viktil KK, Blix HS, Moger TA, Reikvam A. Polypharmacy as commonly defined is an indicator of limited value in the assessment of drug-related problems. Br J Clin Pharmacol. 2007 Feb;63(2):187-95. doi: 10.1111/j.1365-2125.2006.02744.x.

8. Nobili A, Licata G, Salerno F, Pasina L, Tettamanti M, Franchi C, De Vittorio L, Marengoni A, Corrao S, Iorio A, Marcucci M, Mannucci PM; SIMI Investigators. Polypharmacy, length of hospital stay, and in-hospital mortality among elderly patients in internal medicine wards. The REPOSI study. Eur J Clin Pharmacol. 2011 May;67(5):507-19. doi: 10.1007/s00228-010-0977-0.

9. Chun JC, Appel SJ, Simmons S. 2015 Beers criteria medication review in assisted living facilities. J Am Assoc Nurse Pract. 2018 Nov;30(11):648-54. doi: 10.1097/JXX.0000000000000082.

10. Bulatova N, Elayeh E, Abdullah S, Halaseh L, Abuloha S, Raqeeq MA, Aldaghlise D, Alrbeihat G. Assessment of inappropriate medication use in Jordanian elderly hospitalized patients using 2015 Beers criteria. Turkish Journal of Geriatrics. 2019;22(3):258-68. doi: 10.31086/ tjgeri.2019.101. 